\title{
Trematodes on acid: editorial comment on the feature article by Guilloteau et al.
}

\author{
Thorsten B. H. Reusch ${ }^{1}$
}

Received: 7 March 2016 / Accepted: 8 March 2016 / Published online: 11 April 2016

(C) Springer-Verlag Berlin Heidelberg 2016

The field of ocean acidification (OA) research is moving rapidly, moving from studying first-order direct effects of lowered $\mathrm{pH}$ and carbonate ion concentration impinging directly upon organismal physiology to ask how species interactions are modified. How host-parasite interactions may be modulated by ocean acidification is currently largely unknown, in particular for macroparasites (=metazoan animal parasites). This is unfortunate, given that these interactions are among the strongest biological interactions in all ecosystems, while their food web role, in particular in coastal systems, is often neglected (but see Kuris et al. 2008).

Digenean trematodes are one of the most abundant and diversified groups of macroparasites worldwide, displaying a breathtaking diversity of two- or three-phasic life cycles (Galaktionov and Dobrovolskij 2003). Often, the first intermediate host is a mollusc (snail or bivalve), followed by a fish as second intermediate host, and a mammal or bird species as third and definitive host where sexual reproduction takes place. In this issue of Marine Biology, the study by Guilloteau et al. (2016) focused on the mollusc host phase where the infective parasite stages rapidly multiply via clonal proliferation, a critical step for generating millions of free-swimming cercariae. Note that in the case of the two model species in the study by Guilloteau et al. (2016) cercariae leave out the 2 nd intermediate host and encyst directly on benthic surfaces to become

Responsible Editor: U. Sommer.

Thorsten B. H. Reusch

TReusch@geomar.de

1 Evolutionary Ecology, GEOMAR Helmholtz Centre for Ocean Research Kiel, 24105 Kiel, Germany metacercariae, awaiting ingestion by the definitive host. For the first time, Guilloteau and co-authors studied how OA would alter the performance of infective stages within snails. They found that lower $\mathrm{pH}$ increased the production of cercariae in both species, with a possible trade-off of smaller sizes over a 2-month experimental period. The longevity of encysted metacercariae assessed over a 30-day interval was reduced in the one (Philophthalmus) but not in the other species (Parorchis). These strong speciesspecific effects highlighted that currently, no generalizations are possible with respect to $\mathrm{OA}$ effects on marine trematodes.

As a fascinating zoological curiosity, their model species Philophthalmus and Parorchis display caste diversification. Some individuals develop into smaller morphotypes that defend the larger clonal proliferators against competing trematode species (so-called soldiers). As a result of experimental ocean acidification, the cast ratios were biased towards fewer defensive stages, again an effect that was species specific. Philophthalmus showed the highest proportion of small 'soldier' morphotypes at intermediate acidification levels, while in Parorchis, fewer defensive stages were found at the lowest $\mathrm{pH}$. The observed effects most likely have consequences for parasite transmission rates and hence for the prevalence of these species within the diverse host species.

Taken together these results highlight both the need to address how the inevitable progression of dissolved $\mathrm{CO}_{2}$ into the ocean as a result of anthropogenic burning of fossil fuels alters species interactions beyond competition (James et al. 2014), grazing (Borell et al. 2013) and predation (Kroeker et al. 2014), namely the neglected field of hostparasite interactions. Another valuable next step would be to assess the long-term evolutionary consequences of acidification on the equilibrium of hosts and parasites (Sunday 
et al. 2014), as well as including more than one component of global change, i.e. warming and acidification. Finally, such experimental data are urgently needed to complement epidemiological assessments on the possible increase of marine disease as a consequence of global change.

\section{References}

Borell EM, Steinke M, Fine M (2013) Direct and indirect effects of high pCO2 on algal grazing by coral reef herbivores from the Gulf of Aqaba (Red Sea). Coral Reefs 32:937-947

Galaktionov KV, Dobrovolskij AA (2003) The biology and evolution of trematodes. Kluwer Academic Publishers, Dordrecht

Guilloteau P, Poulin R, MacLeod CD (2016) Impacts of ocean acidification on multiplication and caste organisation of parasitic trematodes in their gastropod host. Mar Biol. doi:10.1007/ s00227-016-2871-5

James RK, Hepburn CD, Cornwall CE, McGraw CM, Hurd CL (2014) Growth response of an early successional assemblage of coralline algae and benthic diatoms to ocean acidification. Mar Biol 161:1687-1696

Kroeker KJ, Sanford E, Jellison BM, Gaylord B (2014) Predicting the effects of ocean acidification on predator-prey interactions: a conceptual framework based on coastal molluscs. Biol Bull 226(3):211-222

Kuris AM, Hechinger RF, Shaw JC, Whitney KL, Aguirre-Macedo L, Boch CA, Dobson AP, Dunham EJ, Fredensborg BL, Huspeni TC, Lorda J, Mababa L, Mancini FT, Mora AB, Pickering M, Talhouk NL, Torchin ME, Lafferty KD (2008) Ecosystem energetic implications of parasite and free-living biomass in three estuaries. Nature 454:515-518

Sunday JM, Calosi P, Dupont S, Munday PL, Stillman JH, Reusch TBH (2014) Evolution in an acidifying ocean. Trends Ecol Evol 29:117-125 